\title{
The Effect of Combined Therapy with Fenugreek and Nutrition Training Based on Iranian Traditional Medicine on FBS, HgA1c, BMI, and Waist Circumference in Type 2 Diabetic Patients: A Randomized Double-Blinded Clinical Trial
}

\author{
Seyyedeh Seddigheh Hassani ${ }^{1(\mathbb{D})}$, Faramarz Fallahi Arezodar ${ }^{2,3}$, Seyyed Saeid Esmaeili ${ }^{* *(\mathbb{D})}$, \\ Mohammad Gholami-Fesharaki 4 iD \\ 1. Dept. of Iranian Traditional Medicine, Faculty of Medicine, Shahed University, Tehran, Iran \\ 2. Dept. of Cardiology, Faculty of Medicine, Shahed University, Tehran, Iran \\ 3. Immunoregulation Research Center, Shahed University, Tehran, Iran \\ 4. Dept. of Biostatistics, Faculty of Medical sciences, Tarbiat Modares University, Tehran, Iran
}

\begin{tabular}{l}
\hline Article Info \\
\hline doi $10.30699 /$ jambs.27.120.37 \\
\hline $\begin{array}{c}\text { Received: } 2018 / 08 / 22 ; \\
\text { Accepted: } 2019 / 02 / 07 ; \\
\text { Published Online: 07 Feb } 2019 ;\end{array}$ \\
\hline $\begin{array}{r}\text { Use your device to scan and read the } \\
\text { article online }\end{array}$ \\
O
\end{tabular}

Corresponding Information: Seyyed Saeid Esmaeili, Dept. of Iranian Traditional Medicine, Faculty of Medicine, Shahed University, Tehran, Iran

Email:Dr.esmaeili@chmail.ir

\begin{abstract}
Background \& Objective: Diabetes mellitus (DM) is one of the most common metabolic disorders that cause a high annual cost of patients care and health services in a society. Given the fact that DM management is very important, the present study aims to investigate the effect of combined therapy with fenugreek and nutrition training based on Iranian traditional medicine on FBS, $\mathrm{HgAlc}, \mathrm{BMI}$, and waist circumference in type 2 diabetic patients.
\end{abstract}

Materials \& Methods: This randomized double blinded clinical trial was conducted on patients with type 2 diabetes in Tehran (Iran) during 2017. Patients were randomly divided into four groups, including: G1 [fenugreek powder (10g/two times per day) with nutrition training), G2 [wheat flour (placebo) with nutrition training), G3 [fenugreek powder $(10 \mathrm{~g} / \mathrm{two}$ times per day) without nutrition training], and $\mathrm{G} 4$ [wheat flour (placebo) without nutrition training].

Results: This study was done on 125 patients (43\% male and 57\% female). There was no significant difference in demographic characteristics of all groups. The mean of FBS in G1, G2, G3 and G4 significantly decreased by 62, 12, and 23 units, respectively $(P<0.001)$. The mean of $\mathrm{HbA1c}$ in groups $\mathrm{G} 1, \mathrm{G} 2$, and $\mathrm{G} 3$ declined by $0.77,0.31$ and 0.5 units, respectively. The mean of BMI in groups G1, G2, and G3 decreased by $1.38,0.82$ and 0.89 units, respectively. Furthermore, waist circumference reduced in all of three groups by $7.11,3.8$ and 3.18 units, respectively. There was no significant change in mean value of these parameters in G4 group.

Conclusion: Given the positive effect of fenugreek and nutrition training on FBS, HbA1c, BMI, and waist circumference, it can be suggested for blood glucose control in diabetic patients. Interestingly, combined therapy with fenugreek and nutrition training was more effective in reducing blood glucose, indicating the importance of this combined therapy for blood glucose control in DM patients.

Keywords: Fenugreek, Type 2 Diabetes, Nutrition training, Iranian traditional medicine

Copyright $\odot$ 2018, This is an original open-access article distributed under the terms of the Creative Commons Attribution-noncommercial 4.0 International License which permits
copy and redistribution of the material just in noncommercial usages with proper citation.

\section{Introduction}

Diabetes mellitus (DM) is one of the most common non-communicable metabolic disorders (1-3). The incidence of DM has been increased in recent years. It is estimated to be increased from 285 million in 2010 to about 371 million in 2012. However, it is assumed that DM will increase to about 552 million in 2030. Changes in lifestyle, aging, overweight, low physical activity, and economic status are the most important risk factors associated with DM (4). Oral glycemic and injectable drugs (e.g. insulin) have been suggested for treatment of DM disease; however, administration of these drugs may be associated with several side effects such as diarrhea, nausea, bloating, severe hypoglycemia, overweight, and hepatic damages. Modern medicine has also recommended nutrition training program besides drug orders to keep blood glucose at a balanced level (3). Despite standard drug therapy and guidelines, blood glucose is not regulated at a balanced level. Some studies demonstrated that nearly $36-69 \%$ of DM patients don't receive normal blood glucose level even after drug administrations. Similar to modern medicine, Iranian Traditional Medicine has suggested that the principle of staying health (particularly nutrition training) is very important in the prevention and treatment of various 
diseases $(3,5)$. Since this is more effective than drug therapy, Iranian scholars have paid a particular attention to this program for the prevention and treatment of various diseases (6). In traditional medicine, plant-based drugs not only have been used for improving the quality of life but also, they have been used for the treatment of diabetes. Fenugreek, with a scientific name of Trigonella FoenumGraceum, is a medicinal plant and an annual herb of Leguminosae which is commonly used as an anti-diabetic drug. Fenugreek is considered a blood glucose reducing plant in Iranian Traditional Medicine resources $(7,8)$. Some of in vivo studies demonstrated that Fenugreek is effective in reducing the blood glucose without any side effects $(7,8)$. Several studies showed that Fenugreek is effective for reducing the blood glucose and fat (9-13). Recent studies have revealed that Fenugreek also reduces insulin resistance and subsequently regulates blood glucose in patients with type 2 diabetes mellitus (TDM) $(1,14)$. The reason for such effectiveness for fenugreek can be justified that fenugreek containing effective steroids, alkaloids and trigonellin compounds, It helps to inhibit sodium glucose uptake and subsequently reduce blood glucose levels (15). Given the anti-diabetic effect of Fenugreek, it can be used as an inexpensive and safe natural drug for treatment of diabetes $(14,16)$. Although several lines of studies evaluated the effectiveness of Fenugreek on various diseases, less information is available about combined therapy with Fenugreek and nutrition training based on Iranian traditional medicine on $\mathrm{FBS}, \mathrm{HbA}_{1} \mathrm{C}, \mathrm{BMI}$, and waist circumference in type 2 diabetic patients. Therefore, in this study, we aim to consider the effect of this combined therapy on these parameters in patients with TDM.

\section{Materials and Methods}

This randomized clinical trial study was conducted in Tehran city within 2017. TDM Patients who referred to Diabetes Association in Tehran, Health Center of Iranian Traditional Medicine (Shahed University) and private clinics in Tehran, were entered into the study. After the initial evaluation of about 22,000 (from Diabetes Association), 5,000 (from Health Center of Iranian Traditional Medicine) and 8,000 (from private clinics) medical documents, approximately 1000 TDM patients were selected based on our inclusion and exclusion criteria. Approximately 260 patients agreed to participate in this survey after phone contacts. Finally, 144 of patients were entered into the survey based on study criteria. All selected patients were admitted at regional medical centers in Tehran and then signed a consent letter before the study. A questionnaire containing data on demographic characteristics was provided for all patients and then their weight, height, and waist circumference were recorded. Blood $\mathrm{FBS}$ and $\mathrm{HbA}_{1} \mathrm{C}$ were measured using glucose test apparatus (Easy Gluco) and Clover A1C analyzer (Infopia Company, Korea), respectively. Patients who met the following criteria were entered into the study: 1: willingness to participate in this survey, 2: age ranged from 35 to 70 years, 3: having at least a 6month history of diabetes, 4 : $\mathrm{BMI}<35 \mathrm{~kg} / \mathrm{m}^{2}, 5$ : kidney failure and 6: use of glycemic drugs but not insulin at the time of study. The exclusion criteria including: 1: pregnant or lactation women, 2: infectious diseases (e.g. pneumonia, urinary infection, and sepsis) with leukocytosis and neutrophilic, 3: history of other diseases such as malignancies, rheumatologic diseases, hormonal disease, 4: smoking or alcohol consumption, 5: unwilling participants, 6: sensitivity to plant drugs, and 7: ketoacidosis and chronic hyperglycemia. At the time of the study, all patients were clinically stable and had not experienced any use of plant-based drugs. After the selection of patients, they were randomly divided into four groups, including: G1 [fenugreek powder (10g/two times per day) with nutrition training), G2 [wheat flour (placebo) with nutrition training), G3 [fenugreek powder (10g/two times per day) without nutrition training], and G4 [wheat flour (placebo) without nutrition training]. Patients in all groups had also continued their classic treatments according to their physician's instructions. Information about their nutritional training habitats was gathered using phone contact. All patients in each group were admitted to our center on day 0 , as well as second, third, sixth and eighth weeks in order to measure weight, FBS, HbA1C, and waist circumference. In this study, the weight and waist circumference were measured on 0 , sixth and eighth weeks, while FBS and $\mathrm{HbA}_{1} \mathrm{C}$ were evaluated in 0 and eight weeks. The Ethics Review Board of the Shahed University approved the study (IR.shahed.REC.1395.234). This study also is registered and confirmed at the Iranian Registry of Clinical Trials (IRCT2017052233590N4).

\section{Drug Design and Intervention}

Fenugreek with the scientific name of Trigonella Foenum-Graceum (herbarium code from Shahid Beheshti Medical Science University was SMMU-8078) was purchased from a reliable grocery, grinded and then weighed using a balance with $0.001 \mathrm{~g}$ accuracy. Fenugreek powder were packed into several blinded packets (17-19). A total of 120 packets, each containing 5 g Fenugreek powder, were provided. At the initial phase of the study, 60 packets were posted to each patient, and one month later the other 60 packets were delivered to them. Wheat flour was provided in similar methods for the placebo group. Patients in Fenugreek groups received 5 grams of Fenugreek powder and placebo group 5 grams of wheat flour for a consecutive of two months (two times per day before the start of the meal).

\section{Nutrition Training Program}

In this study, the nutritional training contents were extracted and programmed according to the Iranian tradition medicine and Imam al-Ridha. All patients were informed about the nutritional training program in a face to face meeting. Patients participated in this class in a group of 10 people for two hours. In this class, all patients were informed about their daily nutritional training. The instructions for nutritional training are summarized as follow:

1- Signs of appetite when beginning to eat (20)

2- Signs of appetite when finishing eating (20) 
3- No immediate change in food habits even for those who have bad diet habits $(20,21)$

\section{4- Feeling well after eating but not boredom (20)}

The number of meals: three meals in two days. On the first day, breakfast and dinner will be served but on the second day only lunch (after 8 hours of the day) (20)

5- Choose the right food (Warm-tempered persons must eat cold foods and cold-tempered individuals must eat warm foods) (20)

5-1- Don't eat different sorts of foods in a meal $(20,21)$

5-2-Being calm and quiet during eating (20)

5-3- Chewing properly the food (22)

5-4- Start eating with light foods and then with heavy foods (20)

5-5-Don't drink water immediately after eating (at least $1.5 \mathrm{~h}$ after a meal); immediate water drinking causes indigestion; however, persons with a nature of warm stomach may have benefits $(20,21)$

\section{5-6- Don’t fall sleep immediately after eating (22).}

The compliance rate of patients to this nutritional training program was evaluated by an expert specialist physician in traditional medicine. All patients were also reminded about their nutritional training program via a popular network for a period of two months. Patients in the irrelevant educational group were trained about the anatomical and muscular function of the gastrointestinal system.

\section{Statistical Analysis}

A descriptive (mean and standard deviation, correlation, frequency, and ratio) and inferential statistics (Chi-square test, t-test, Mann-Whitney $U$ test, paired t-test, and Wilcoxon test) were applied for data analysis. Data were normalized using the K-S test. SPSS 21 (SPSS Inc., Chicago, IL., USA) was applied for data analysis. A Pvalue $<0.05$ is considered significant. A total of 30 samples were calculated in each group based on $n=2\left(Z_{\frac{\alpha}{2}}+\right.$ $\left.Z_{\beta}\right)^{2} / d^{2}$ formula. In this formula $\alpha=0.05, \beta=0.1$ and $\mathrm{d}=0.6$. In order to $20 \%$ samples dropping, 6 samples were added to each group. Eventually, 36 samples were entered into each group.

\section{Results}

A total of 144 patients were entered into the study, 125 of whom could eventually complete the survey (Figure 1). Basic demographic data of all patients are shown in Table 1. Non-significant differences were found in a mean of age, sex frequency, educational levels and other basic data between all groups. The mean \pm SD of FBS and $\mathrm{HgA} 1 \mathrm{C}$ before and after interventions in each group is summarized in Table 2. The mean of FBS in G1, G2, and G3 was significantly decreased by 62,12 , and 23 units, respectively $(P<0.001)$. The mean of $\mathrm{HbA} 1 \mathrm{C}$ in groups G1, G2, and G3 was declined by $0.77,0.31$ and 0.5 units, respectively. Additionally, the mean of BMI in groups G1, G2, and G3 was decreased by $1.38,0.82$ and 0.89 units, respectively (Table 3 ). Waist circumference was reduced in all of three groups by 7.11, 3.8 and 3.18 units, respectively. There was no significant change in the mean value of these parameters in group G4.

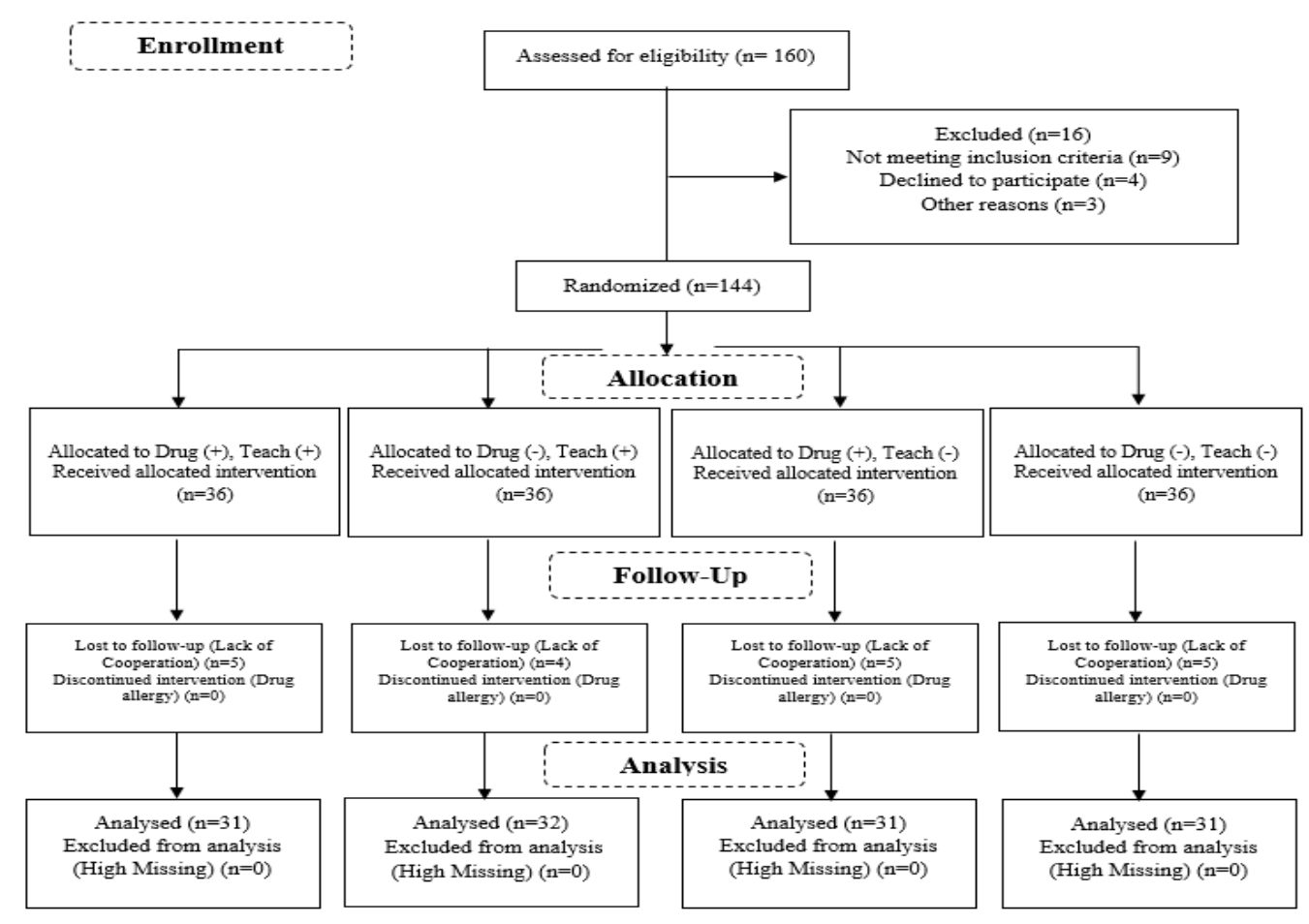

Figure 1. Follow up diagram 
Table 1. The frequency and percent of gender, education, BMI and mean and SD of age and baseline variable according to the four groups

\begin{tabular}{|c|c|c|c|c|c|c|c|c|c|c|}
\hline \multirow{2}{*}{\multicolumn{2}{|c|}{ Categorical variables }} & \multicolumn{2}{|c|}{ G1 } & \multicolumn{2}{|c|}{ G2 } & \multicolumn{2}{|c|}{ G3 } & \multicolumn{2}{|c|}{ G4 } & \multirow{2}{*}{ P-value } \\
\hline & & $\mathrm{N}$ & $\%$ & $\mathrm{~N}$ & $\%$ & $\mathrm{~N}$ & $\%$ & $\mathrm{~N}$ & $\%$ & \\
\hline \multirow{4}{*}{ Gender } & Female & 22 & $71.0 \%$ & 18 & $56.3 \%$ & 17 & $54.8 \%$ & 14 & $45.2 \%$ & \multirow{2}{*}{0.231} \\
\hline & Male & 9 & $29.0 \%$ & 14 & $43.8 \%$ & 14 & $45.2 \%$ & 17 & $54.8 \%$ & \\
\hline & Under Diploma & 6 & $19.4 \%$ & 11 & $34.4 \%$ & 7 & $22.6 \%$ & 5 & $16.1 \%$ & \multirow{4}{*}{0.112} \\
\hline & Diploma & 11 & $35.5 \%$ & 8 & $25.0 \%$ & 12 & $38.7 \%$ & 4 & $12.9 \%$ & \\
\hline \multirow[t]{2}{*}{ Education } & $\begin{array}{c}\text { Associate Degree } \\
\text { or BA }\end{array}$ & 10 & $32.3 \%$ & 6 & $18.8 \%$ & 9 & $29.0 \%$ & 12 & $38.7 \%$ & \\
\hline & MD or Ph.D. & 4 & $12.9 \%$ & 7 & $21.9 \%$ & 3 & $9.7 \%$ & 10 & $32.3 \%$ & \\
\hline \multirow[t]{2}{*}{ BMI } & $<=25.00$ & 8 & $25.8 \%$ & 3 & $9.4 \%$ & 7 & $22.6 \%$ & 13 & $41.9 \%$ & \multirow{2}{*}{0.028} \\
\hline & $25.01+$ & 23 & $74.2 \%$ & 29 & $90.6 \%$ & 24 & $77.4 \%$ & 18 & $58.1 \%$ & \\
\hline \multicolumn{2}{|c|}{ Continues variables } & Mean & SD & Mean & SD & Mean & $\mathrm{SD}$ & Mean & SD & P-value \\
\hline Age & Year & 50.19 & 8.57 & 52.81 & 8.02 & 51.23 & 8.78 & 51.32 & 7.35 & 0.652 \\
\hline $\begin{array}{l}\text { Diabetes } \\
\text { length }\end{array}$ & Year & 6.76 & 4.34 & 6.91 & 3.11 & 5.74 & 3.05 & 7.10 & 4.08 & 0.476 \\
\hline WC & $\mathrm{Cm}$ & 97.61 & 11.32 & $\begin{array}{c}101.9 \\
1\end{array}$ & 10.15 & 98.05 & 9.82 & 95.05 & 8.56 & 0.061 \\
\hline FBS & $\mathrm{mg} / \mathrm{dl}$ & $\begin{array}{c}164.5 \\
8\end{array}$ & 53.14 & $\begin{array}{c}173.2 \\
2\end{array}$ & 48.85 & $\begin{array}{c}149.7 \\
4\end{array}$ & 42.15 & $\begin{array}{c}154.4 \\
8\end{array}$ & 39.41 & 0.188 \\
\hline $\mathrm{HgA} 1 \mathrm{C}$ & $\mathrm{mmol} / \mathrm{mol}$ & 8.19 & 1.86 & 8.42 & 1.21 & 7.96 & 1.80 & 7.86 & 1.54 & 0.524 \\
\hline
\end{tabular}

G1: Drug (yes), Education (yes); G2: Drug (no), Education (yes); G3: Drug (yes), Education (no); G4: Drug (no), Education (no);

The P-value base on Chi-Square test, ANOVA or Kruskal-wallis H Test; SD: Standard Deviation

Table 2. The Mean and SD of FBS and HgA1C before and after of study according to the 4 groups

\begin{tabular}{|c|c|c|c|c|c|c|c|c|}
\hline & & \multicolumn{2}{|c|}{ Before } & \multicolumn{2}{|c|}{8 week } & \multirow{2}{*}{ Diff } & \multirow{2}{*}{ P-value } & \multirow{2}{*}{ P-value } \\
\hline & & Mean & SD & Mean & SD & & & \\
\hline \multirow{4}{*}{ FBS } & G1 & 164.58 & 53.14 & 102.52 & 16.28 & -62.06 & $<0.001$ & \multirow{4}{*}{$<0.001$} \\
\hline & $\mathrm{G} 2$ & 173.22 & 48.85 & 160.63 & 45.12 & -12.59 & $<0.001$ & \\
\hline & G3 & 149.74 & 42.15 & 126.59 & 28.34 & -23.15 & $<0.001$ & \\
\hline & G4 & 154.48 & 39.41 & 153.58 & 37.11 & -0.90 & 0.316 & \\
\hline \multirow{4}{*}{$\mathrm{HgA} 1 \mathrm{C}$} & G1 & 8.19 & 1.86 & 7.42 & 1.21 & -0.77 & $<0.001$ & \multirow{4}{*}{$<0.001$} \\
\hline & G2 & 8.42 & 1.21 & 8.11 & 1.06 & -0.31 & $<0.001$ & \\
\hline & G3 & 7.96 & 1.80 & 7.46 & 1.35 & -0.50 & $<0.001$ & \\
\hline & G4 & 7.86 & 1.54 & 7.81 & 1.50 & -0.05 & 0.033 & \\
\hline
\end{tabular}

G1: Drug (yes), Education (yes); G2: Drug (no), Education (yes); G3: Drug (yes), Education (no); G4: Drug (no), Education (no);

Table 3. The Mean and SD of BMI and WC before, 6 weeks and 8 weeks after of study according to the 4 groups

\begin{tabular}{|c|c|c|c|c|c|c|c|c|c|c|c|c|}
\hline \multirow{3}{*}{ Variables } & \multirow{3}{*}{ Group } & \multicolumn{6}{|c|}{ Time } & \multirow{2}{*}{\multicolumn{2}{|c|}{6 week -Before }} & \multirow{2}{*}{\multicolumn{2}{|c|}{$\begin{array}{l}8 \text { week - } \\
\text { Before }\end{array}$}} & \multirow{3}{*}{ P-value } \\
\hline & & \multirow{2}{*}{$\begin{array}{l}\text { Before } \\
\text { Mean }\end{array}$} & \multicolumn{3}{|c|}{6 week } & \multicolumn{2}{|c|}{8 week } & & & & & \\
\hline & & & SD & Mean & $\mathrm{SD}$ & Mean & SD & Diff & P-value & Diff & $\mathrm{P}$-value & \\
\hline \multirow{4}{*}{ BMI } & G1 & 27.43 & 2.92 & 26.50 & 2.82 & 26.05 & 2.62 & -0.93 & $<0.001$ & -1.38 & $<0.001$ & \multirow{4}{*}{$<0.001$} \\
\hline & $\mathrm{G} 2$ & 28.21 & 2.43 & 27.61 & 2.26 & 27.39 & 2.27 & -0.6 & $<0.001$ & -0.82 & $<0.001$ & \\
\hline & G3 & 26.64 & 1.86 & 26.05 & 1.85 & 25.75 & 1.89 & -0.59 & $<0.001$ & -0.89 & $<0.001$ & \\
\hline & G4 & 25.31 & 1.91 & 25.10 & 1.90 & 25.21 & 1.87 & -0.21 & 0.001 & -0.1 & 0.016 & \\
\hline \multirow{4}{*}{ WC } & G1 & 97.61 & 11.32 & 93.71 & $\begin{array}{c}10.2 \\
0\end{array}$ & 90.50 & 9.25 & -3.9 & $<0.001$ & -7.11 & $<0.001$ & \multirow{4}{*}{$<0.001$} \\
\hline & G2 & 101.91 & 10.15 & 99.47 & 9.94 & 98.11 & 10.00 & -2.44 & $<0.001$ & -3.8 & $<0.001$ & \\
\hline & G3 & 98.05 & 9.82 & 95.74 & 8.54 & 94.87 & 8.90 & -2.31 & $<0.001$ & -3.18 & $<0.001$ & \\
\hline & G4 & 95.05 & 8.56 & 94.58 & 8.37 & 95.00 & 8.65 & -0.47 & 0.078 & -0.05 & 0.884 & \\
\hline
\end{tabular}

G1: Drug (yes), Education (yes); G2: Drug (no), Education (yes); G3: Drug (yes), Education (no); G4: Drug (no), Education (no); 


\section{Discussion}

In order to get an inexpensive and more effective strategy for the treatment of TDM, we investigated the effect of combined therapy with Fenugreek and nutrition training based on Iranian traditional medicine on FBS, $\mathrm{HgA1C}$, BMI, and waist circumference in type 2 diabetic patients. Our data have shown that combined therapy with Fenugreek and nutrition training was more effective for reducing the FBS, $\mathrm{HgA1C}$, BMI, and waist circumference in type 2 diabetic patients. Although the use of Fenugreek and nutrition training separately decreased the mean levels of FBS, $\mathrm{HgA1C}$, BMI, and waist circumference, Fenugreek was more effective. Our findings are in accordance with results from previous research that showed the positive effect of Fenugreek $(13,23,24)$ and nutrition training $(20,25-29)$ for the blood glucose control. In the clinical trial study, Kasaeian et al. (30).demonstrated that Fenugreek can be used as a medicinal plant along with other therapeutic methods for the treatment of diabetes. The anti-diabetic effect of Fenugreek is likely due to the existence of different chemical compounds such as steroids, alkaloids and trigonelline which decrease intestinal absorption of glucose in a Na-dependent manner $(15,31)$. These chemical compounds have also antioxidant and antiinflammatory properties which inhibit oxidation of DNA and lipids $(32,33)$. Also we can tell that, the effects of anti-diabetes and reducing the cholesterol of fenugreek seeds are largely attributed to saponins and high fiber content, which is due to delay in gastric emptying due to saponin complex with fiber content and with unknown components that carbohydrate digestive enzymes constraints are related (34). Given the anti-oxidative properties of these chemical compounds, they can scavenge reactive oxygen species (ROS) radicals and subsequently prevent tissue damage and also glycation, as a critical stage in proliferation, migration, disruption and vascular endothelial cells death. Since fenugreek has anti-inflammatory properties, it can be used for the treatment of overweight and TDM. Several lines of studies showed that fenugreek has anti-diabetic properties without any side effects $(7,8)$. For these reasons, numerous studies have recommended this medicinal plant for blood glucose control.

Previous studies showed that an appropriate nutritional training program is very useful for blood glucose and $\mathrm{HgA} 1 \mathrm{c}$ control (25). Given the valuable effect of the nutritional training program in blood glucose control, this therapeutic method can be suggested for diabetic patients. Since combined therapy with fenugreek and appropriate nutritional training program is more effective to mitigate FBS and $\mathrm{HgAlc}$, fenugreek can be used as a supplementary drug along with nutritional training program for blood glucose control. The strength of the current study is related to its blinded status, evaluation of the effect of combined therapy with fenugreek and nutritional training program on FBS, HgA1C, BMI, waist circumference in TDM patients with appropriate sample size.

\section{Conclusion}

Given the positive effect of fenugreek and nutrition training on FBS, HbA1C, BMI, and waist circumference, it can be suggested for blood glucose control in diabetic patients. Interestingly, combined therapy with fenugreek and nutrition training was more effective in reducing blood glucose, indicating the importance of this combined therapy for blood glucose control in DM patients.

\section{Acknowledgements}

The authors thank all those who helped them writing this paper.

\section{Conflict of Interest}

Authors declared no conflict of interests.

\section{References}

1. Ahmadi A, Hasanzadeh J, Rahimi Madiseh M, Lashkari L Effective factors in the quality of life in patients with type 2 diabetes in Chaharmahal \& Bakhteyari Province. Journal of north Khorasan University of medical sciences. 2011; 3(17): 713. [DOI:10.29252/jnkums.3.1.1]

2. Corriere M, Rooparinesingh N, Kalyani RR. Epidemiology of diabetes and diabetes complications in the elderly: an emerging public health burden. J Current Diabet Report. 2013; 13(6): 80513. [DOI:10.1007/s11892-013-0425-5] [PMID] [PMCID]

3. Kasper D, Fauci AS, Hauser SL, Longo DL, Jameson JL, Loscalzo J. Harrisons manual of medicine: McGraw-Hill Medical Publishing Division; 2016.

4. Guariguata L. By the numbers: New estimates from the IDF Diabetes Atlas Update for 2012. Diabetes Res Clin Pract. 2012; 98(3): 524-5. [DOI:10.1016/j.diabres.2012.11.006] [PMID]

5. Venkat Narayan K, Gregget E, Fagot Campagna A, Vinicor F. Diabetes a common, growing, serious, and potentially preventable, public health problem. J Diabet Resh Clin Prac. 2000; 2: 577-84. [DOI:10.1016/S0168-8227(00)00183-2]

6. Ravankhah N, Mirzaei R, Masoum S. Spatial eco-risk assessment of heavy metals in the surface soils of industrial city of Aran-o-Bidgol, Iran. Bull Environ Contam Toxicol. 2016; 96(4): 516-23. [DOI:10.1007/s00128-016-1761-3] [PMID]

7. Shojaii A, Dabaghian FH, Goushegir A, Fard MA. Antidiabetic plants of Iran. Acta Medica Iranica. 2011; 49(10): 637-42.

8. Uemura T, Hirai S, Mizoguchi N, et al. Diosgenin present in fenugreek improves glucose metabolism by promoting adipocyte differentiation and inhibiting inflammation in adipose tissues. Molecu Nut Food Res. 2010; 54(11): 1596-608. [DOI:10.1002/mnfr.200900609] [PMID] 
9. Hamden K, Keskes H, Elgomdi O, Feki A, Alouche N. Modulatory effect of an isolated triglyceride from fenugreek seed oil on of $\alpha$-amylase, lipase and ACE activities, liver-kidney functions and metabolic disorders of diabetic rats. J Oleo Sci. 2017; 66(6): 633-45. [DOI:10.5650/jos.ess16254] [PMID]

10. Mooventhan A, Nivethitha L. A narrative review on evidencebased antidiabetic effect of fenugreek (Trigonella FoenumGraecum). Int J Nut Pharmacol Neurologic Dis. 2017; 7(4): 84. [DOI:10.4103/ijnpnd.ijnpnd 36 17]

11. Nagulapalli Venkata KC, Swaroop A, Bagchi D, Bishayee A. A small plant with big benefits: Fenugreek (Trigonella foenumgraecum Linn.) for disease prevention and health promotion. Mol Nutrition Food Res. 2017; 61. [DOI:10.1002/mnfr .201600950] [PMID]

12. Ranade M, Mudgalkar N. A simple dietary addition of fenugreek seed leads to the reduction in blood glucose levels: A parallel group, randomized single-blind trial. Ayu. 2017; 38(1-2): 24-27. [DOI:10.4103/ayu.AYU 209 15] [PMID] [PMCID]

13. Roberts KT. The potential of fenugreek (Trigonella foenumgraecum) as a functional food and nutraceutical and its effects on glycemia and lipidemia. J Med Food. 2011; 14(12): 1485-9. [DOI:10.1089/jmf.2011.0002] [PMID]

14. Al-Habori M, Raman A. Antidiabetic and hypocholesterolaemic effects of fenugreek. Phytother Res. 1998; 12(4): 233-42. [DOI:10.1002/(SICI)1099-1573(199806)12:43.0.CO;2-V]

15. Al-Habori M, Raman A, Lawrence M, Skett P. In vitro effect of fenugreek extracts on intestinal sodium-dependent glucose uptake and hepatic glycogen phosphorylase A. J Diabet Res. 2001; 2: 91-9. [DOI:10.1155/EDR.2001.91] [PMID] [PMCID]

16. Suchitra M, Parthasarathy S. Effect of administration of fenugreek seeds on $\mathrm{HbA1C}$ levels in uncontrolled diabetes mellitus-a randomized controlled trial. Int J Pharm Tech Res. 2015; 8(2): 180-2.

17. Morcos S, Elhawary Z, Gabrial G. Protein-rich food mixtures for feeding the young in Egypt 1. Formulation. Z Ernährungswiss. 1981; 20(4): 275-82. [DOI:10.1007/BF02021639] [PMID]

18. Yadav UC, Baquer NZ. Pharmacological effects of Trigonella foenum-graecum L. in health and disease. Pharmaceut Biol. 2014; 52(2): 243-54. doi: 10.3109/13880209.2013.826247. [DOI:10.3109/13880209.2013.826247] [PMID]

19. Żuk-Gołaszewska K, Wierzbowska J. Fenugreek: productivity, nutritional value and uses. J Elementol. 2017; 22(3): 1067-80. [DOI:10.5601/jelem.2017.22.1.1396]

20. Esmaeili SS, Fallahi F, Fesharaki MG, Noormohammadi G. A randomized trial on the effect of Razavi's dietary pattern on the components of metabolic syndrome. Iran Red Crescent Med J. 2014; 16(3): e14601. Iran. [DOI:10.5812/ircmj.14601] [PMID]

21. Borhani M, Khoshzaban F, Jodeiri B, Naseri M, Kamalinejad M. Diet and food in Iranian traditional medicine: Hints for further research. Int J Prevent Med. 2014; 5(11): 1480-1.

22. Nimrouzi M, Zare M. Principles of nutrition in Islamic and traditional Persian medicine. J Evid Based Complementary
Altern Med. 2014; 19(4): 267-70. [DOI:10.1177/215658 7214542006] [PMID]

23. Gupta A, Gupta R, Lal B. Effect of Trigonella foenum-graecum (Fenugreek) seeds on glycaemic control and insulin resistance in type 2 diabetes. J Assoc Physicians India. 2001; 49: 1057-61.

24. Madar Z. Fenugreek (Trigonella foenumgraecum) as a means of reducing postprandial glucose level in diabetic rats [Trigonella foenum-graecum]. Nut Report Int. 1984.

25. Osborn CY, Amico KR, Cruz N, et al. A brief culturally tailored intervention for Puerto Ricans with type 2 diabetes. Health Educ Behav. 2010; 37(6): 849-62. [DOI:10.1177/1090198110366004] [PMID] [PMCID]

26. Müller JE, Sträter-Müller D, Marks H-J, Gläsner M, Kneppe P, Clemens-Harmening B, et al. Carbohydrate restricted diet in conjunction with metformin and liraglutide is an effective treatment in patients with deteriorated type 2 diabetes mellitus: Proof-of-concept study. Nut Metab. 2011; 8(1): 92. [DOI:10.1186/1743-7075-8-92] [PMID] [PMCID]

27. Navas-Carretero S, Abete I, Zulet MA, Martínez JA. Chronologically scheduled snacking with high-protein products within the habitual diet in type-2 diabetes patients leads to a fat mass loss: a longitudinal study. Nut J. 2011; 10(1): 74. [DOI:10.1186/1475-2891-10-74] [PMID] [PMCID]

28. Bayan Z, Bou Aj, Karimi Ki. Effectiveness of cognitivebehavioral religious-cultural therapy in improvement of obsessive-compufsive patients. Razi J Med Sci. 2005.

29. Ahn HJ, Han KA, Kwon HR, et al. Small rice bowl-based meal plan versus food exchange-based meal plan for weight, glucose and lipid control in obese type 2 diabetic patients. Korean Diabetes J. 2010; 34(2): 86-94. [DOI:10.4093/kdj.2010.34.2.86] [PMID] [PMCID]

30. Kasaeian N, Forghani BA, EMAMI T, AMINI M. The effect of consumption of Fenugreek seeds on fasting blood Glucose, glycosylated Hemoglobin and serum Lipids in type II diabetic patients. Tabriz Univ Med J Sci. 2003; 58: 69-73

31. Kawabata T, Cui M-Y, Hasegawa T, Takano F, Ohta T. Antiinflammatory and anti-melanogenic steroidal saponin glycosides from Fenugreek (Trigonella foenum-graecum L.) seeds. Planta Med. 2011; 77(07): 705-10. [DOI:10.1055/s-0030-1250477] [PMID]

32. Kaviarasan S, Naik G, Gangabhagirathi R, Anuradha C, Priyadarsini K. In vitro studies on antiradical and antioxidant activities of fenugreek (Trigonella foenum graecum) seeds. Food Chem. 2007; 103(1): 31-7. [DOI:10.1016/j.foodchem.2006.05.064]

33. Madar Z, Stark AH. New legume sources as therapeutic agents. Br J Nut. 2002; 88(S3): 287-92. [DOI:10.1079/BJN2002719] [PMID]

34. Abedinzadeh M, Nikokar I, Nasri S, Amal Omidi M, Nursabaghi F. Effect of hexanic and alcoholic extracts of fenugreek seed in male diabetic rats. Zahedan J Res Med Sci. 2013; 15: 50-30.

\section{How to Cite This Article:}

Hassani S S, Fallahi A, Esmaeili S S, Gholami Fesharaki M. The Effect of Combined Therapy with Fenugreek and Nutrition Training Based on Iranian Traditional Medicine on FBS, HgAlc, BMI, and Waist Circumference in Type 2 Diabetic Patients: a Randomized Double Blinded Clinical Trial . J Adv Med Biomed Res. 2019; 27 (120) :37-42 